\title{
PREDICTION OF GREENHOUSE MICRO-CLIMATE USING ARTIFICIAL NEURAL NETWORK
}

\author{
SINGH, V. K. ${ }^{*}-$ TIWARI, K. N. \\ Dept. of Agricultural and Food Engineering, \\ Indian Institute of Technology Kharagpur, West Bengal, India \\ *Corresponding author \\ e-mail:vikas3234@gmail.com,vikas@agfe.iitkgp.ernet.in \\ (Received $22^{\text {nd }}$ Oct 2016; accepted $28^{\text {th }}$ Jan 2017)
}

\begin{abstract}
The aim of this study is to develop an Artificial Neural Network (ANN) model for prediction of one day ahead mean air temperature and relative humidity of greenhouse located in the sub-humid sub-tropical regions of India. The adequacy of back propagation neural network to model the inside temperature and humidity of a production greenhouse as a function of micro-climatic parameters including temperature, relative humidity, wind speed, and solar radiation was addressed. Micro-climatic data of greenhouse and outside were collected on daily basis and used for analysis of best fit ANN model. After the network structure and parameters were determined reasonably, the network was trained. The activation functions were respectively the hyperbolic tangent in the hidden layer and the linear function in the output layer. The Root Mean Square Error (RMSE), Mean Absolute Error (MAE) and Correlation Coefficient were chosen as the statistical criteria for measuring of the network performance. A comparison was made between measured and predicted values of temperature and relative humidity, and the results showed that the BP neural network (for network (6-4-2) model given a best prediction for inside temperature and relative humidity. Statistical analysis of output shows that, the RMSE and Mean Absolute Error (MAE) between the measured and predicted temperature was 0.711 ${ }^{\circ} \mathrm{C}$ and $0.558{ }^{\circ} \mathrm{C}$, and the relative humidity RMSE and MAE was $2.514 \%$ and $1.976 \%$ which can satisfy with the demand of greenhouse climate control.
\end{abstract}

Keywords: ANN, temperature, relative humidity, wind speed, solar radiation

\section{Introduction}

Prediction of temperature and relative humidity under the greenhouse is a complex process and a challenging task for researchers. The inside temperature and relative humidity of the greenhouse is one of the key parameters that directly influence the crop production. Prediction of ambient temperature can be useful in the thermal analysis of greenhouse enabling heating and cooling load calculations. The prediction and control of temperature and relative humidity is also important to maintain other micro climatic parameters at acceptable level, for reducing plant stress, checking growth of harmful organisms and to improve heating system. The greenhouse microclimate is a typical complicated nonlinear system, which provides plants with good environmental conditions for growing. ANN models have been applied in controlled environments like greenhouse and glasshouse to predict micro-climatic parameters such as temperature, relative humidity etc. (He and Ma, 2010; Seginer et al., 1994; Seginer, 1997; Linker and Seginer, 2004; Parsons, 2009). ANN does not require any prior knowledge of the system under consideration and are well suited to model dynamical systems on a real time basis. It is, therefore, possible to set up systems so that they would adapt to the events which are observed and for this, it is useful in real time analyses, e.g., weather forecasting, different fields of predictions, etc. (Devi et al., 2012). ANN provides a methodology for solving many types of non-linear problems that are difficult to solve by traditional techniques. ANN has capability to extract the relationship between the 
inputs and outputs of a process. Thus, these properties of ANN are well suited to the problem of weather forecasting under consideration (Ahmad et al., 2014). Its applications are numerous in various fields including engineering, management, health, biology and even social sciences (Diaz et al., 2001; Imran et al., 2002; Topalli and Erkmen, 2003; Islamoglu, 2003; Gwo-Ching et al., 2004; Yalcinoz and Eminoglu, 2005; Lauret et al., 2008; Jassar et al., 2009).

Frausto, and Pieters (2004) and Linker and Seginer (2004) trained a neural network using experimental data to model the internal temperature of greenhouse and they found that ANN model has great potential to predict the temperature under the greenhouse with very less degree of error. Behrang et al. (2010) developed Multi-layer perceptron (MLP) and radial basis function (RBF) neural networks for daily global solar radiation prediction. They considered various meteorological variables including Daily mean air temperature, relative humidity, sunshine hours, evaporation, and wind speed values between 2002 and 2006 for Dezful city in Iran. The results of comparison between ANN and other prediction methods showed ANN suitability in prediction due to less Mean Absolute Percentage Error (MAPE). Imran et al. (2002) used ANN for the prediction of hourly mean values of ambient temperature $24 \mathrm{~h}$ in advance. This neural network is trained off-line using back propagation and batch learning scheme. The trained neural network is successfully tested on temperatures for years other than the one used for training. It requires one temperature value as input to predict the temperature for the following day for the same hour.

The aim of this study is to develop an Artificial Neural Network (ANN) model to predict greenhouse mean temperature and relative humidity in one day advance using inputs as maximum and minimum temperature (T) and relative humidity (RH) of greenhouse, outside average wind speed (WS) and solar radiation (RS).

\section{Materials and Methods}

\section{Experimental Greenhouse}

The experimental sawtooth shape naturally ventilated greenhouse (N-S oriented) cladded with $200 \mu$ diffused (PAR transmissivity of $90 \%$ and $42 \%$ diffusivity) film was fabricated and installed at the Field Water Management Laboratory of Agricultural and Food Engineering Department, Indian Institute of Technology Kharagpur, India (Figure 1).

Micro-climatic parameters such as temperature, relative humidity and solar radiation under greenhouse and outside were recorded and analyzed. Automatic weather station of M/S Campbell Scientific, Canada comprising a data-logger (model CR1000) and sensors were installed in the greenhouse to monitor air temperatures \& relative humidity (model HMP 45 C), global radiation and Photosynthetically Active Radiation (SPLITE and PARLITE of Kipp and Zonen). The outside micro-climatic parameters such as temperature, solar radiation and wind speed were recorded manually using handheld instruments.

\section{Data and Methodology}

In this study, the daily micro climatic data of greenhouse and outside conditions for the years 2011- 2015 were used to train and test the model for prediction of one day ahead greenhouse mean temperature and relative humidity. The inputs for model were 
maximum and minimum temperature $(\mathrm{T})$, and relative humidity $(\mathrm{RH})$ of greenhouse, outside average wind speed (WS) and solar radiation (RS) however outputs were one day ahead greenhouse mean temperature and relative humidity. Neural networks generally provide improved performance with the normalized data. The use of original data as input to neural network may cause a convergence problem (Khan and Ondrusek, 2000). All the weather data sets were therefore transformed into values between -1 and 1 through dividing the difference of actual and minimum values by the difference of maximum and minimum values (Litta et al., 2013). At the end of algorithm, outputs were denormalized into the original data format for achieving the desired result. After pre-processing of data set in desired time lag format, three different data sets were extracted from the input and target data for training, validation and test phase. Training set consists of 60 percent of data to build the model and determine the parameters such as weights and activation function, validation data set includes 15 percent to measure the performance of network by holding constant parameters. Finally, 25 percent of data is used to increase the robustness of model in the test phase. Analysis of daily temperature and relative humidity data of greenhouse is presented in Figure 2 and 3 respectively. It can be seen from Figure 2, the maximum and minimum temperature of greenhouse varies from $45.5{ }^{\circ} \mathrm{C}$ to $18{ }^{\circ} \mathrm{C}$ and $32{ }^{\circ} \mathrm{C}$ to $6{ }^{\circ} \mathrm{C}$ respectively whereas the mean temperature varies from $37{ }^{\circ} \mathrm{C}$ to $12{ }^{\circ} \mathrm{C}$. Daily mean relative humidity of greenhouse varies from $84 \%$ to $31 \%$. Outside daily solar radiation and wind speed data is presented in Figure 4

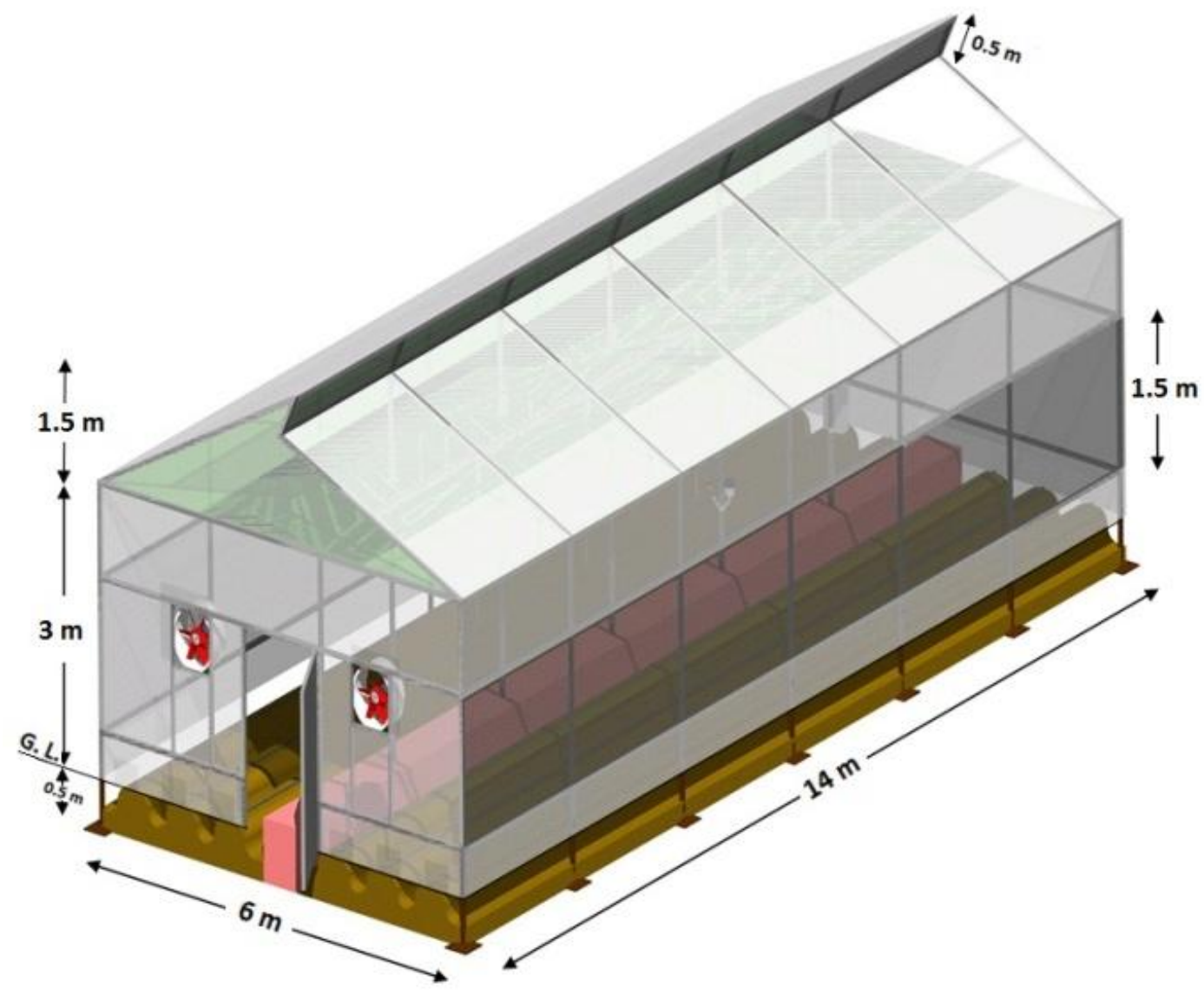

Figure 1. Layout of experimental greenhouse 


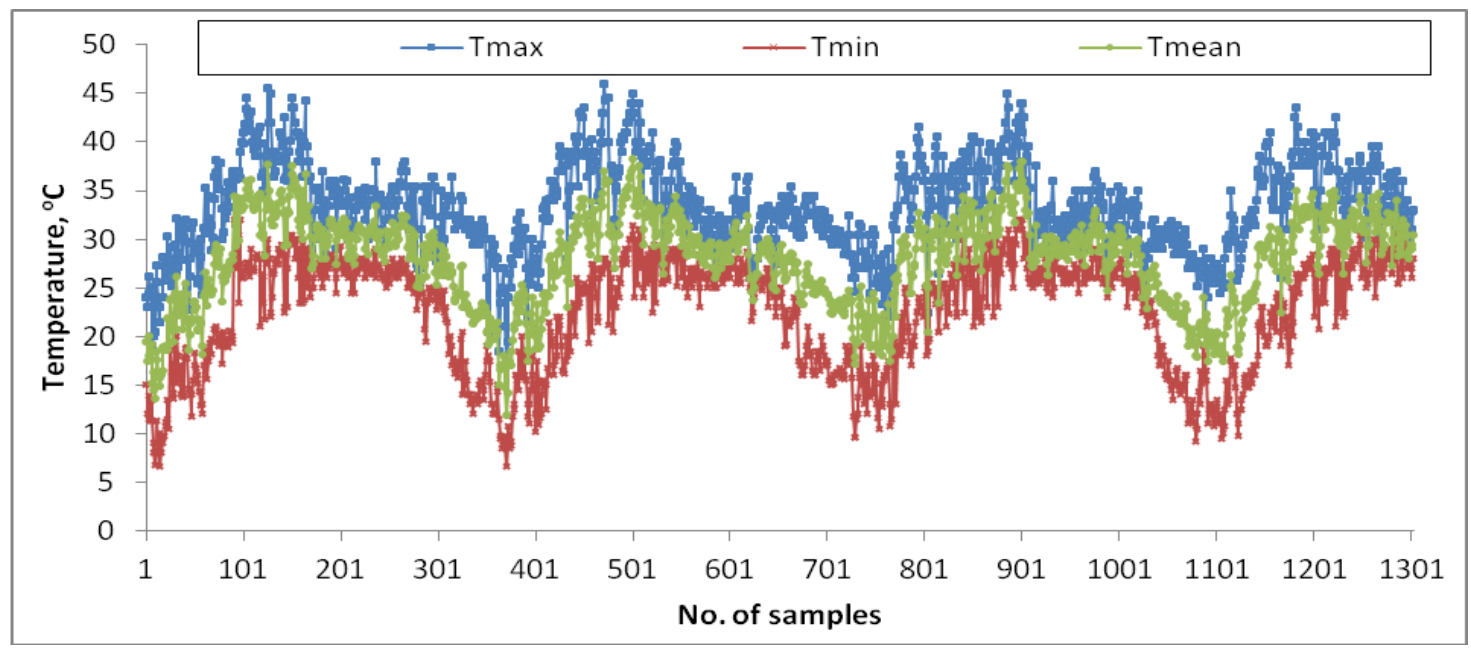

Figure 2. Maximum, minimum and mean temperature of greenhouse

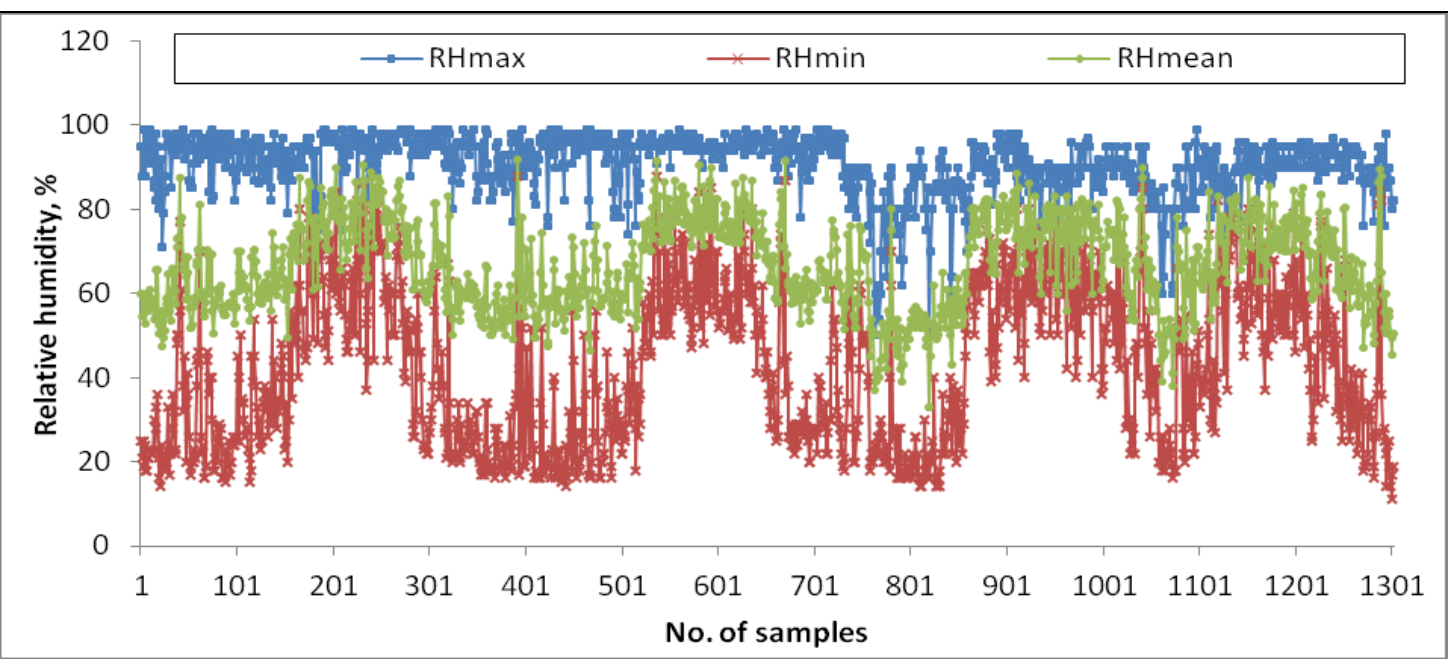

Figure 3. Maximum, minimum and mean relative humidity of greenhouse

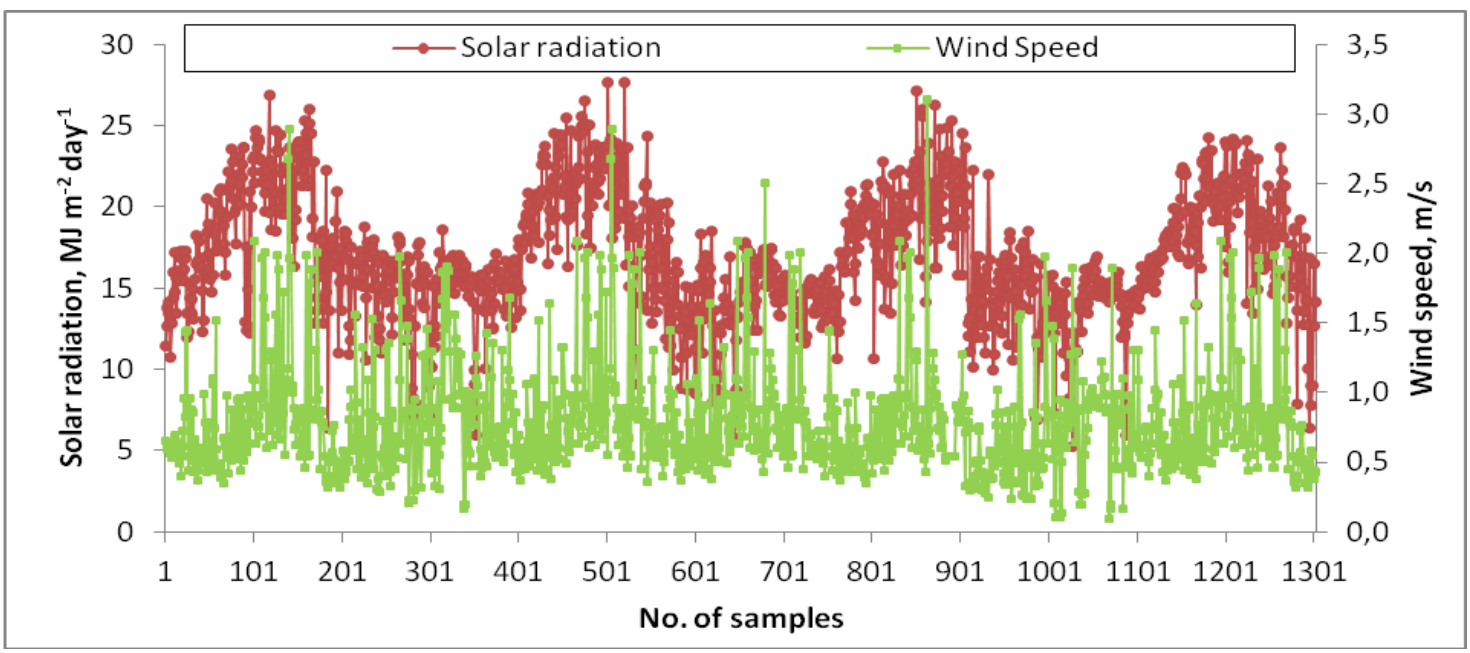

Figure 4. Outside daily solar radiation and wind speed experimental data 


\section{Determination of Neural Network Structure}

Experimental data were used to determine the optimal ANN structure and simulations were carried out using Neurosolutions software developed by Neuro Dimensions Inc. of Florida. In order to determine the optimal network architecture, various network architectures were designed; the number of neurons in the hidden layer and transfer functions in hidden/output layer was changed. Based on the Kosmogorov approaching theory, the BP neural network with a single hidden layer including a sufficient number of neurons can approximate any function with the desired accuracy; the neural network with only one hidden layer was chosen (He et al., 2007; Said, 1992; Imran et al., 2002). According to the factors affecting the greenhouse micro-climate, the network input layer neuron was set as 6 . The output layer neuron was 2 . For the determination of number of neurons in the hidden layer, we chosen different number of neurons of hidden layer to try after inputting the same training and validating data. For each network RMSE, MAE and $\mathrm{R}^{2}$ values of the outputs were calculated and compared. Table 1 was the error comparison of different ANN structure. When the number of neurons in hidden layer was 4 , the network output error was smallest, which showed the network structure was better. According to analysis, the neural network model was 3 layers BP neural network with the structure of 6-4-2. A typical architecture of ANN model showing inputs and output of this study is presented in Figure 5. The learning rate $\eta$ is taken to be 0.9 .

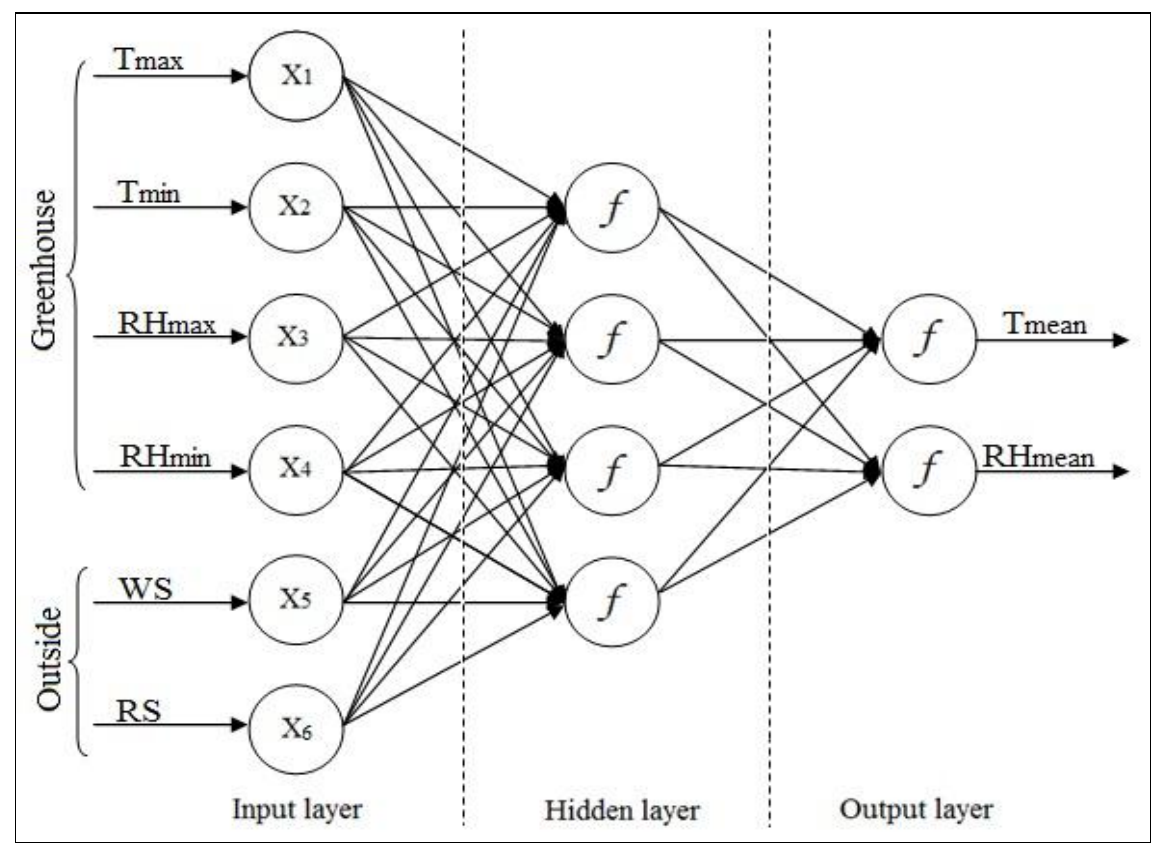

Figure 5. The architecture of ANN model

\section{Training of the Network}

Training of the network was performed using Levenberg-Marquardt feed-forward back propagation algorithms. It is the fastest and ensures the best convergence to a minimum of mean square error (MSE) for function approximation problems (Sahai et al., 2000, 2003). The flow chart of ANN prediction system is presented in Figure 6. Then, the ANN models were tested and the results were compared by means of correlation coefficient and root mean square error (RMSE) statistics. The best suited network was selected based on the minimized 
values of root mean square error (RMSE), and the maximum value of correlation coefficient (CC). Root Mean Square Error (RMSE), Mean Absolute Error (MAE), $\mathrm{R}^{2}$ and correlation coefficient statistics were used to measure the performance of the models.

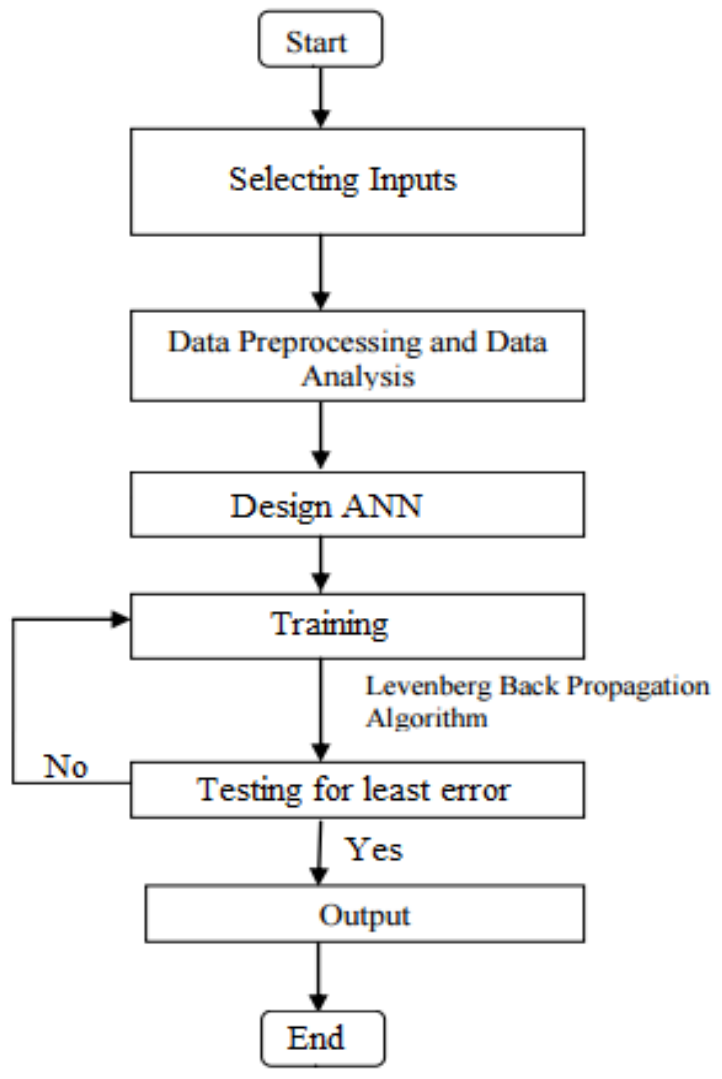

Figure 6. Flowchart of prediction system

Let $x_{i}(\mathrm{i}=1,2, \ldots \mathrm{n})$ are inputs and $w_{i}(\mathrm{i}=1,2, \ldots \mathrm{n})$ are respective weights. The net input to the node can be expressed as Equation 1:

$$
\text { net }=\sum_{\mathrm{i}=1}^{\mathrm{n}} x_{i} w_{i}
$$

The net input is then passed through an activation function $f($.$) and the output \mathrm{y}$ of the node is computed as $y=f($ net $)$.

A three-layer structure (one input layer, one hidden layer, and one output layer) was selected with hyperbolic tangent (tanh) transfer function for hidden layer and linear transfer function for output layer. Therefore, an ANN with 6 inputs, $h$ hidden neurons and two output units defines a nonlinear parameterized mapping from an input $x$ to an output $y$ given by the following relationship (Equation 2):

$$
y=y(x, w)=\sum_{j=0}^{h}\left[w_{j} \cdot f\left(\sum_{i=0}^{6} w_{j i} x_{i}\right)\right]
$$


There are two main steps to obtain the ANN optimal model: The learning phase and the generalization phase. During the learning phase, the ANN is trained using a training dataset of $\mathrm{N}$ inputs and output.

The vector $x$ contains samples of each of the six input variables. The variable $t$, also called the target variable, is the corresponding measurement of the temperatures. This phase consist of adjusting $w$ so as to minimize an error function $J$, which is usually the sum of square errors between the experimental output $t_{i}$ and the ANN model output, $y=$ $y\left(x_{i} ; w\right)$ (Equation 3):

$$
J(w)=\frac{1}{2} \sum_{i=1}^{N}\left\{y_{i}-t_{i}\right\}^{2}=\frac{1}{2} \sum_{i=1}^{N} e^{2}
$$

The second phase is the generalization phase. It consists of evaluating the ability of the ANN model to replicate the observed phenomenon, that is, to give correct outputs when it is confronted with examples that were not seen during the training phase.

The performance measure is usually given by the linear correlation coefficient (r), coefficient of determination $\left(\mathrm{R}^{2}\right)$, mean absolute error (MAE) and root mean square error (RMSE) (Equation 4, 5, 6, and 7):

$$
\begin{gathered}
r=\frac{n \sum \hat{\mathrm{y}} y-\left(\sum \hat{\mathrm{y}}\right)\left(\sum y\right)}{\sqrt{n\left(\sum \hat{\mathrm{y}}^{2}\right)-\left(\sum \hat{\mathrm{y}}\right)^{2}} \sqrt{n\left(\sum y^{2}\right)-\left(\sum y\right)^{2}}} \\
R^{2}=1-\frac{\sum_{i=1}^{n}\left(y_{i}-\hat{\mathrm{y}}_{i}\right)^{2}}{\sum_{i=1}^{n}\left(y_{i}-\overline{\mathrm{y}}_{i}\right)^{2}} \\
\text { MAE }=\frac{1}{n} \sum_{i=1}^{n}\left|\hat{\mathrm{y}}_{i}-y_{i}\right| \\
R M S E=\sqrt{\sum_{i=1}^{n}\left[\frac{\left(\hat{\mathrm{y}}_{i}-y_{i}^{2}\right)}{n}\right]}
\end{gathered}
$$

Where, $\hat{y}$ is predicted value, $y$ is measure value, $\bar{y}$ is the mean of measured variables and $\mathrm{n}$ is the number of samples.

\section{Results and Discussion}

The ANN model was trained using the daily micro-climatic data of the years 20112014, and the trained model was then tested with the daily micro-climatic data of the year 2015. This process was begun with a network which had 3 neurons in its hidden layer, and repeated, increasing the number of neurons up to 10. The calculated Root Mean Squared Error (RMSE), Mean absolute Error (MAE) and fraction of variance $\left(\mathrm{R}^{2}\right)$ 
values of the errors of the ANN forecasted daily mean temperatures and relative humidity are listed in Table 1, for each network. The LM algorithm with 4 neurons in the hidden layer for network (6-4-2) has produced the best results, and it is used for generating the graphical outputs.

Mean square error (MSE) during training and cross validation period is presented in Figure 7. The back propagation Training-Error graph explains that the error is high when the iteration is less and vice versa. In the graph mentioned in Figure 7, it explains that when the iteration count is below 400 the training MSE is greater and when the count reaches 600 the error is minimum and constant till 1000 iteration. This results that for more accurate results, the iteration count should be high.

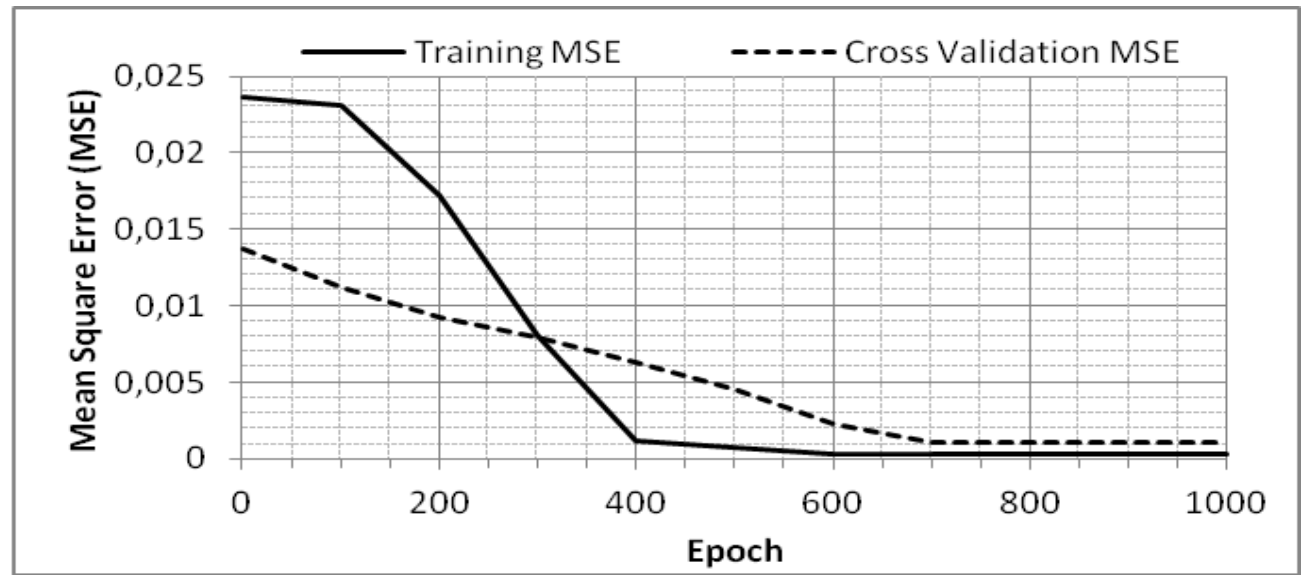

Figure 7. Convergence of error (MSE) with Epoch during training and cross validation

Figure 8 and Figure 9 are the comparison curves between measured and predicted values of the inside temperature and relative humidity. Figure 10 and Figure 11 were the fit curves between measured and predicted inside temperature and relative humidity. From the results shown in Figure 8 and Figure 9 it is observed that the predicted values are in good agreement with measured values and the predicted error is very less. The predictions of greenhouse temperature and relative humidity results simulated using the developed ANN model were strongly correlated with the experimental data. Therefore the proposed MLP Back Propagation Neural Network model with the developed structure can perform good prediction with least error.

By utilizing the RMSE algorithm to analyze the values, the RMSE and Mean absolute Error (MAE) between the measured and predicted temperature was $0.711{ }^{\circ} \mathrm{C}$ and $0.558{ }^{\circ} \mathrm{C}$ respectively, and between the measured and predicted relative humidity it was $2.514 \%$ and $1.976 \%$, which illuminated the neural network model had the ability to predict the inside mean temperature. The coefficient of determination $\left(\mathrm{R}^{2}\right)$ obtained from the regression line between the measured and predicted temperature and relative humidity was found to be 0.980 and 0.967 respectively. The results demonstrated the neural network model can predict the change of micro-climate of greenhouse accurately. It is clear from test result that the higher values of correlation coefficients $(0.989$ and 0.974 for temperature and relative humidity respectively) and lower values of root mean square error suggests the applicability of ANN model for prediction of greenhouse mean temperature and relative humidity. 
Table 1. Variation of RMSE, MAE and $R^{2}$ values with number of hidden neurons in test phase

\begin{tabular}{|c|c|c|c|c|c|c|c|}
\hline \multirow{2}{*}{$\begin{array}{c}\text { Hidden } \\
\text { layer } \\
\text { neurons }\end{array}$} & \multirow{2}{*}{$\begin{array}{c}\text { ANN } \\
\text { structure }\end{array}$} & \multicolumn{2}{|c|}{ RMSE } & \multicolumn{2}{c|}{ MAE } & \multicolumn{2}{c|}{$\mathbf{R}^{\mathbf{2}}$} \\
\cline { 3 - 8 } & $\begin{array}{c}\text { Temperature } \\
\left({ }^{\mathbf{O}} \mathbf{C}\right)\end{array}$ & $\begin{array}{c}\text { R. H. } \\
(\boldsymbol{\%})\end{array}$ & $\begin{array}{c}\text { Temperature } \\
\left(\mathbf{(}^{\mathbf{}} \mathbf{C}\right)\end{array}$ & $\begin{array}{c}\mathbf{R} \text {. H. } \\
(\mathbf{\%})\end{array}$ & Temperature & R. H. \\
\hline 3 & $6-3-2$ & 0.7189 & 2.528 & 0.573 & 1.983 & 0.968 & 0.948 \\
\hline $\mathbf{4}$ & $\mathbf{6 - 4 - 2}$ & $\mathbf{0 . 7 1 1 1}$ & $\mathbf{2 . 5 1 4}$ & $\mathbf{0 . 5 5 8}$ & $\mathbf{1 . 9 7 6}$ & $\mathbf{0 . 9 8 0}$ & $\mathbf{0 . 9 6 7}$ \\
\hline 5 & $6-5-2$ & 0.7145 & 2.537 & 0.564 & 1.992 & 0.973 & 0.956 \\
\hline 6 & $6-6-2$ & 0.7231 & 2.529 & 0.592 & 1.988 & 0.978 & 0.952 \\
\hline 7 & $6-7-2$ & 0.7211 & 2.561 & 0.576 & 2.008 & 0.971 & 0.951 \\
\hline 8 & $6-8-2$ & 0.7119 & 2.582 & 0.568 & 2.095 & 0.965 & 0.945 \\
\hline 9 & $6-9-2$ & 0.7213 & 2.584 & 0.597 & 2.097 & 0.973 & 0.943 \\
\hline 10 & $6-10-2$ & 0.7293 & 2.579 & 0.599 & 2.086 & 0.971 & 0.952 \\
\hline
\end{tabular}

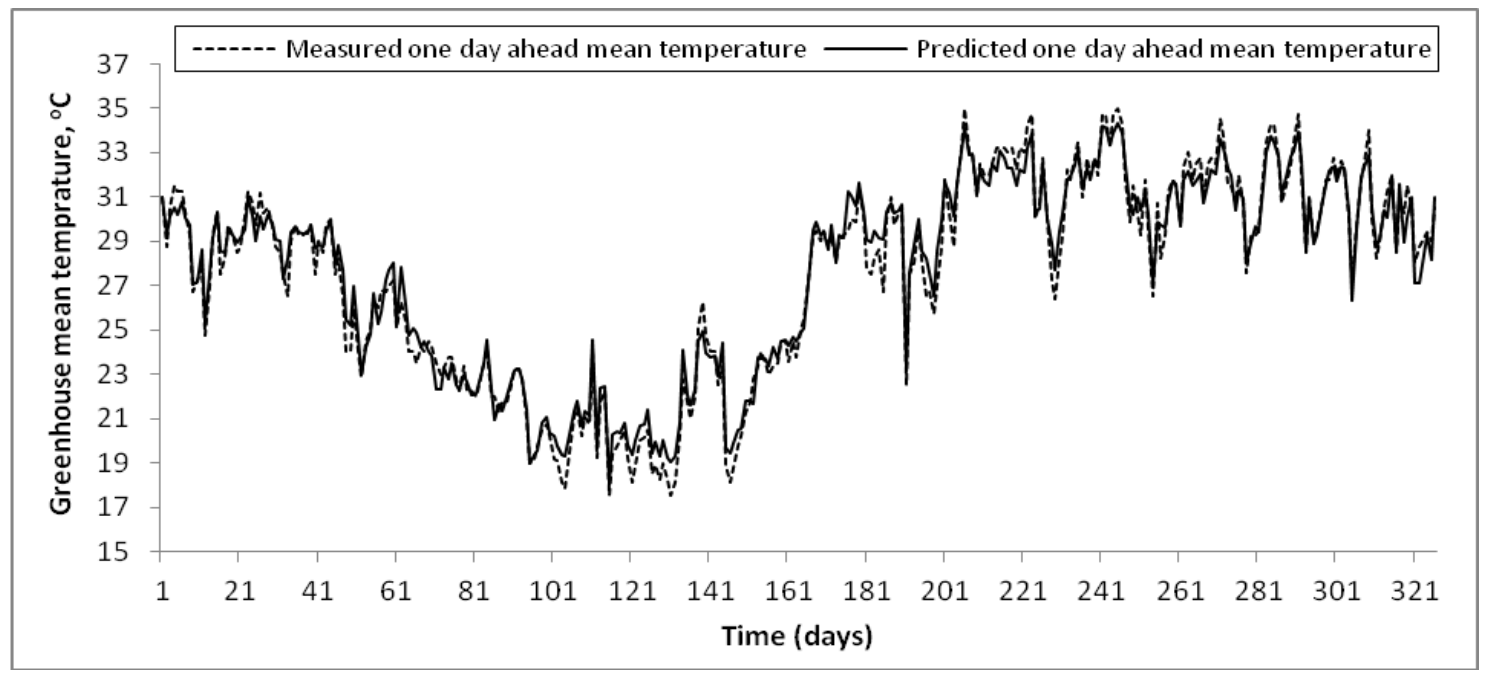

Figure 8. Comparison between one day ahead measured and predicted mean temperature of greenhouse for ANN structure 6-4-2

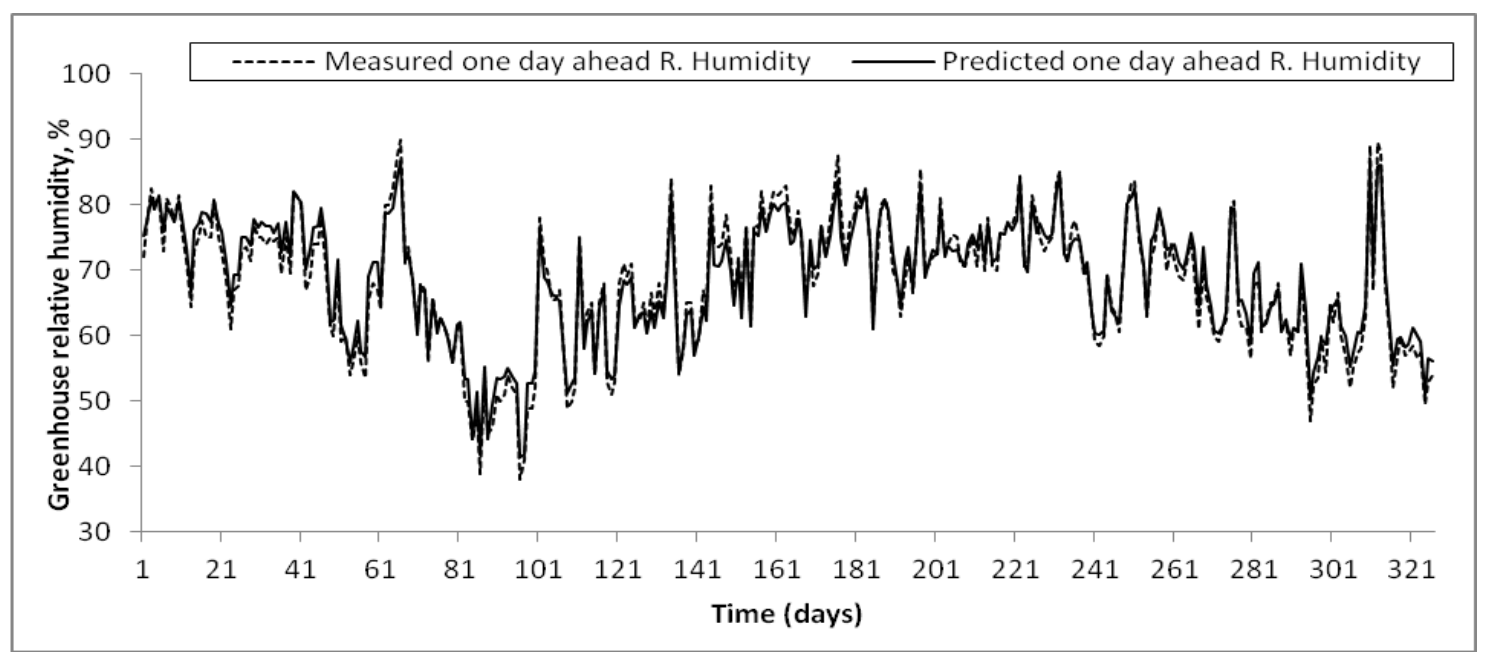


Figure 9. Comparison between one day ahead measured and predicted relative humidity of greenhouse for ANN structure 6-4-2

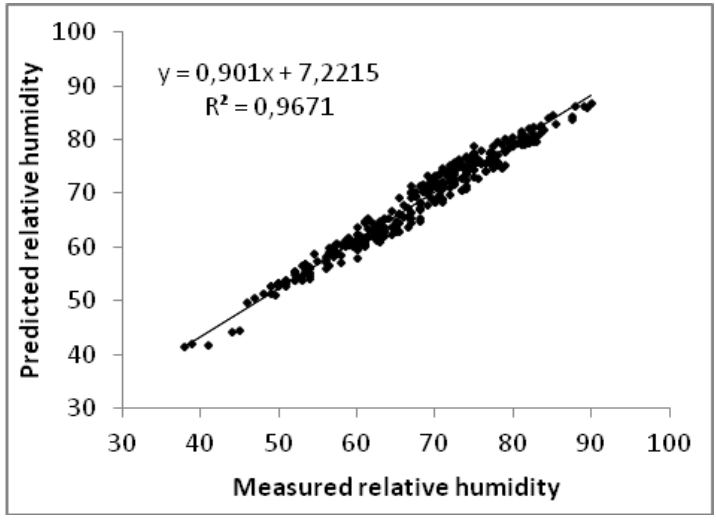

Figure 10. The relationship between measured and predicted mean temperature for ANN structure 6-4-2

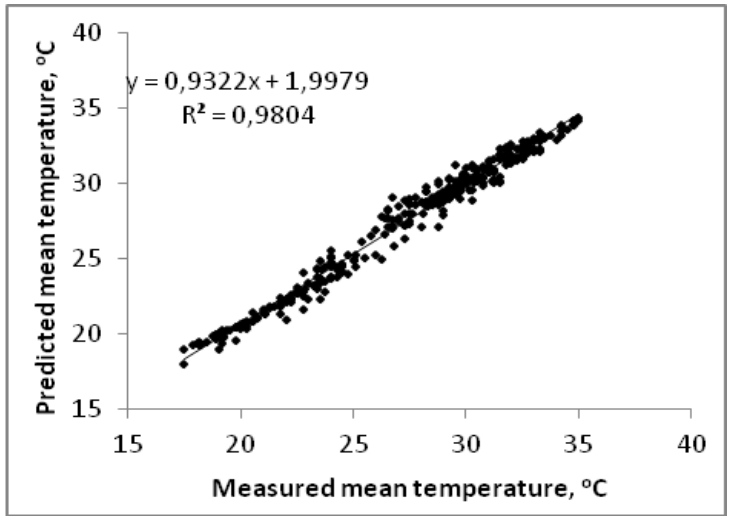

Figure 11. The relationship between measured and predicted relative humidity for ANN structure 6-4-2

\section{Conclusions}

The present study discusses the application and usefulness of artificial neural network based modeling approach in predicating the greenhouse mean temperature and relative humidity. This approach is able to determine the nonlinear relationship that exists between the micro-climatic data (temperature, humidity, wind speed and solar radiation) supplied to the system during the training phase and on that basis, make a prediction of what the temperature and humidity would be in future. A 3-layered neural network is designed and trained with the existing dataset and obtained a relationship between the existing non-linear parameters of micro-climate. Now the trained neural network can predict the future temperature with less error. After 1000 epochs, the Artificial Neural Network has been found to produce a forecast with small prediction error. The study, therefore, establishes that the NN structure with 4 hidden neurons in single layer is the best predictive model over the other structures.

RMSE and MAE statistical indicators showed small values that demonstrates the correct behavior of the developed forecasting models. The values of the correlation coefficient demonstrate the good agreement between predicted and measured values between temperature and humidity.

This study also concludes that a combination of minimum and maximum greenhouse air temperature and relative humidity and outside wind speed and solar radiation provides better performance in predicting the greenhouse temperature and relative humidity for next day. The results are quite encouraging and suggest the usefulness of artificial neural network based modeling technique in accurate prediction of the temperature and relative humidity in the greenhouse.

Acknowledgement. Authors are thankful to the National Committee on Plasticulture Applications in Horticulture (NCPAH), Department of Agriculture, Cooperation and Farmers Welfare, Ministry of Agriculture and Farmers Welfare, Government of India for providing necessary funds and Department of Agricultural and Food Engineering, IIT Kharagpur, India for making available necessary facilities to conduct this research studies. 


\section{REFERENCE}

[1] Ahmad, R., Md. Lazin, N. M., Samsuri, S. F. M. (2014): Neural network modeling and identification of naturally ventilated tropical greenhouse climates -Wseas Transactions on Systems and Control 9: 445-453.

[2] Baboo S. S., Shereef, I. K. (2010): An efficient weather forecasting system using artificial neural network - International Journal of Environmental Science and Development 1(4): 321-326.

[3] Behrang, M.A., Assareh, E., Ghanbarzadeh, A., Noghrehabadi, A. R. (2010): The potential of different artificial neural network (ANN) techniques in daily global solar radiation modeling based on meteorological data -Solar Energy 84: 1468-1480.

[4] Devi, C. J., Reddy, B. S. P., Kumar, K. V., Reddy, B. M., Nayak, N. R. (2012): ANN Approach for Weather Prediction using Back Propagation -International Journal of Engineering Trends and Technology 3(1): 19-23.

[5] Diaz, G., Sen, M., Yang, K. T., McClain, R. L. (2001): On-line training of artificial neural networks for control of a heat exchanger test facility -Proc. National Heat Transfer Conf. 1: 1671-1679.

[6] Dombayc, O. A., Golcu, M. (2009): Daily means ambient temperature prediction using artificial neural network method: A case study of Turkey - Renewable Energy 34: 11581161.

[7] Frausto, H. U, Pieters, J. G. (2004): Modelling greenhouse temperature using system identification by means of neural networks -Neurocomputing 56: 423-428.

[8] Gwo-Ching, L., Ta-Peng, T. (2004): Application of fuzzy neural networks and artificial intelligence for load forecasting -Electric Power System Research 70: 237-244.

[9] Hayati, M., Mohebi, Z. (2007): Application of artificial neural networks for temperature forecasting -World Academy of Science, Engineering and Technology 28.

[10] He, F., Ma, C. (2010): Modeling greenhouse air humidity by means of artificial neural network and principal component analysis -Computers and Electronics in Agriculture 71: 9-23.

[11] He, F., Ma, C., Zhang, J., Chen, Y. (2007): Greenhouse air temperature and humidity prediction based on improved bp neural network and genetic algorithm. D. Liu et al. (Eds.): ISNN 2007, Part III, LNCS 4493: 973-980.

[12] Imran, T., Rehman, S., Bubshait, K. (2002): Application of neural networks for the prediction of hourly mean surface temperatures in Saudi Arabia -Renewable Energy 25: 545-554.

[13] Islamoglu, Y. A. (2003): New approach for the prediction of the heat transfer rate of the wireon- tube type heat exchanger use of an artificial neural network model -Appl. Therm. Eng. 23: 243-249.

[14] Jassar, S., Liao, Z., Zhao, L. (2009): Adaptive neuro-fuzzy based inferential sensor model for estimating the average air temperature in space heating systems -Building and Environment 44: 1609-1616.

[15] Kémajou, A., Mba, L., Meukam, P. (2012): Application of artificial neural network for predicting the indoor air temperature in modern building in humid region -British Journal of Applied Science \& Technology 2(1): 23-34.

[16] Khan, M. R., Ondrusek, C. (2000): Short-term electric demand prognosis using artificial neural networks -Journal of Electrical Engineering 51: 296-300.

[17] Lauret, P., Eric, F., Randrianarivony, R., Manicom, R. J. (2008): Bayesian neural network approach to short time load forecasting -Energy Conversion Management 49: 1156-1166. 
[18] Linker, R., Seginer, I. (2004): Greenhouse temperature modelling: A comparison between sigmoid neural networks and hybrid models -Mathematics and Computers in Simulation 65: 19-29.

[19] Litta, A. J., Idicula, S. M., Mohanty, U. C. (2013): Artificial neural network model in prediction of meteorological parameters during premonsoon thunderstorms -International Journal of Atmospheric Sciences 1-14. http://dx.doi.org/10.1155/2013/525383

[20] Mc Culloch, W.S., Pitts, W. (1943): A logical calculus of the ideas immanent in nervous activity: Bulletin of Math -Biophysics 5: 115-133.

[21] Neuro Dimension Inc. (2005): Developers of Neuro Solutions V5.01: Neural Network Simulator, Neuro Dimension Inc., Gainesville, Fla, USA, http://www.nd.com/

[22] Parsons, N.R., Edmondson, R.N., Song, Y. (2009): Image analysis and statistical modeling for measurement and quality assessment of ornamental horticulture crops in glasshouse -Biosystems Engineering 104: 161-168.

[23] Sahai, A. K., Patanik, D. R., Satyam, V., Grimm, A. M. (2003): Teleconnections in recent time and prediction of Indian summer, monsoon rainfall -Meteorology and Atmos. Phys. 84: 217.

[24] Sahai, A. K., Soman, M. K., Satyam, V. (2000): All India summer monsoon rainfall prediction using an artificial neural network -Climate Dynamics 16: 291.

[25] Said, S. A. M. (1992): Degree-day base temperature for residential building energy prediction in Saudia Arabia -ASHRAE Trans: Res. 98(1): 346-53.

[26] Seginer, I. (1997): Some artificial neural network applications to greenhouse environmental control -Computers and Electronics in Agriculture 18: 167-186.

[27] Seginer, I., Boulard, T., Bailey, B. J. (1994): Neural network models of the greenhouse climate -J. Agric. Eng. Res. (59): 203-216.

[28] Topalli, K. A., Erkmen, I. (2003): A hybrid learning for neural networks applied to short term load forecasting -Neurocomputing 51: 495-500.

[29] Yalcinoz, T., Eminoglu, U. (2005): Short term and medium term power distribution load forecasting by neural networks -Energy Conversion and Management 46: 1393-1405. 